\title{
Benign Metastasizing Leiomyoma of the Uterine Corpus
}

National Cancer Institute

\section{Source}

National Cancer Institute. Benign Metastasizing Leiomyoma of the Uterine Corpus. NCI

Thesaurus. Code C40173.

A cytologically benign smooth muscle neoplasm that arises from the uterine corpus and has metastasized to the lungs, abdomen, or lymph nodes. It usually presents in women with a history of benign uterine leiomyomas that have been surgically removed years before the extrauterine neoplasm spread. 